DOI 10.37882/2223-2982.2020.12.16

\title{
ВЛИЯНИЕ ГЕРОНТОЛОГИЧЕСКИХ ФАКТОРОВ НА ИНТОНАЦИЮ
}

\section{INFLUENCE OF GERONTOLOGICAL FACTORS ON VOICE AND INTONATION}

Yin Xiao

Summary: Age-related changes have a significant impact on the voice and intonation of a person, many different studies have shown that it is very easy to distinguish a «young» voice from an «old» one, this is largely due to physiological changes, for example, with a deterioration in lung function and degradation of the muscles of the larynx. All these physiological changes have a very strong effect on the formation and change of intonation in people at different ages. Using an experimental analysis of such prosodic parameters as the frequency of the main tone, intensity and analysis of the tempo of speech, a study of the influence of gerontological factors on intonation was carried out. The study analyzes sound recordings that were recorded by respondents aged 20 and over, all respondents were divided into four age groups: $20-30$ years old, 40-50 years old, 50-60 years old and people over 65 years old. All research and experimental analyzes in this article are carried out using the PRAAT program developed by two Dutch scientists Paul Boersma and David Weenink at the Phonetic Research Institute of the University of Amsterdam, this program allows you to do, for example, spectral analysis or tone analysis.

Keywords: age, intonation, PRAAT, pitch, intensity, speech rate.

\author{
Инь Сяо \\ Аспирант, Государственный институт русского языка \\ им. А.С. Пушкина, Москва \\ superazhen@hotmail.com
}

Аннотация: Возрастные изменения оказывают значительное влияние на голос и интонацию человека, множество разных исследований доказали, что очень легко отличить «молодой» голос от «старого», во многом это связано с физиологическими изменениями, например, с ухудшением легочных функций и деградацией мышц гортани. Все эти физиологические изменения оказывают очень сильное влияние на формирование и изменение интонации у людей в разном возрасте. Используя экспериментальный анализ таких просодических параметров, как частота основного тона, интенсивность и анализ темпа речи и было проведено исследование влияния геронтологических факторов на интонацию. В исследовании анализируются звукозаписи, которые записали респонденты от 20 лет и старше, все респонденты были поделены на четыре возрастные группы: 20-30 лет, 40-50 лет, 50-60 лет и люди старше 65 лет. Все исследования и экспериментальные анализы в данной статье проводятся с помощью использования программы PRAAT, разработанной двумя Нидерландскими учеными Полом Боерсма и Дэвидом Вининком в институте фонетических исследований Амстердамского университета, эта программа позволяет делать, например, спектральный анализ или анализ тона.

Ключевые слова: возраст, интонация, РRAAT, частота основного тона, интенсивность, темп речи.

\section{Введение}

2 вуковая сторона речевой коммуникации чрезвычайно сложна и разнообразна, она состоит из нескольких этапов, которые изучаются в разных разделах фонетики. Один из разделов фонетики - это акустический раздел. «В акустической фонетике изучаются физические характеристики звуковых единиц» [1, с. 16], например, такие просодические параметры как интенсивность, частота основного тона и темп речи.

«Интенсивность речи - сила произнесения звуков, слов, речевых оборотов, зависящая от условий выступлений, от помещения (в комнате, зале, на площади) и связанная с особенностями речевого дыхания» [2].

Частота основного тона, которую еще обозначают как ЧОТ, Fundamental Frequency или F0 - это частота колебания голосовых связок при произнесении тоновых звуков» [3]. Частота основного тона голоса зависит от «1) напряженности связок, которая регулируется сокращением мышечной части связок (увеличение напряженности повышает ЧОТ) или подъемом перстневидного хряща (поэтому передние гласные более высокие).
2) перепада давлений по обе стороны глоттиса: повышение подсвязочного давления приводит к повышению чОТ (более громкие звуки являются и более высокими» $[1$, c.87].

Используя экспериментальный анализ этих просодических параметров и проводилось исследование влияния геронтологических факторов на интонацию.

Многие научные исследования доказали, что возрастные изменения оказывают сильное влияние на формирование голосовых и интонационных характеристик человека. С возрастом человеческое тело меняется, что, в свою очередь, провоцирует и изменение голоса, это станет особенно заметно, если сравнить голос подростка и голосом старика, любой человек с лёгкостью отличит «старый» голос от «молодого» на слух. Кроме влияния паталогических факторов (например, рака гортани или нейропатии гортани) голос пожилых людей подвергается и другим воздействиям, которые в дальнейшем сказываются на громкость и высоту голоса пожилых людей (когда начинается процесс старения, высоты голоса начинает повышаться, а вот его интенсивность, наоборот, падает). Эти изменения связаны с дегенерацией 
функций легких. Людям в пожилом возрасте необходима боле активная вентиляция, чтобы поддерживать речевую деятельность, это сказывается на скорости речи. Понижение громкости идёт вместе с усилением звуков дыхания, и это ведёт за собой деградацию мышц гортани. Все вышеописанные возрастные изменения, безусловно, сказываются на произношении и интонировании людей. Ниже будет исследовано, как именно возрастные изменения влияют на интонацию людей в разном возрасте.

\section{Экспериментальный анализ}

В данной статье будет представлен, проведённый экспериментальный анализ влияния геронтологических изменений на интонацию. Каким образом вышеописанные факторы проявляются и влияют на интонацию людей разного возраста.

Интонация (от лат. intonare - громко произносить) - это «ритмико-мелодическая сторона речи, служащая в предложении средством выражения синтаксических значений и эмоционально-экспрессивной окраски. Составными элементами интонации являются: мелодики, интенсивности, длительности, темпа речи и тембра произнесения» [4].

В исследовании участвовало 16 человек, по 4 человека в каждой возрастной группе: 20-30 лет, 40-50 лет, 5060 лет и старше 65 лет. Такие группы были выделены в связи с тем, что до 20 лет организм её не до конца сформирован, с 20 до 40 лет не происходит никаких заметных физиологических изменений, способных оказывать влияние на интонацию, а дальше возрастные изменения начинают понемногу оказывать влияние на организм. Считается, что что качественное изменение голоса происходит примерно каждые 10 лет [5, с. 8].

Респондентов попросили прочитать 3 предложения: «В доме коменданта я был принят как родной», «Блажен, кто молча был поэт», «Не приведи Бог увидеть русский бунт бессмысленный и беспощадный»

Поученные материалы были обработаны и проанализированы с помощью программы PRAAT. PRAAT - бесплатный компьютерный программный пакет для анализа речи в фонетике. Программа поддерживает синтез речи, в том числе артикуляционный синтез [6].

Для определения влияния геронтологических изменений на интонацию сначала было проанализировано время, которое потребовалось рецензентам на прочтение каждого предложения (таблицы 1-3), средняя частота основного тона (таблица 4) и средняя интенсивность (таблица 5). В таблицах 4 и 5 указаны средние данные по всем трём предложениям.
Таблица 1.

В доме коменданта я был принят как родной

\begin{tabular}{|c|c|c|c|c|c|}
\hline & Сек. & Сек. & Сек. & Сек. & $\begin{array}{c}\text { Среднее } \\
\text { время про- } \\
\text { чтения }\end{array}$ \\
\hline $20-30$ & 2,871 & 3,12 & 2,74 & 2,9 & 2,90775 \\
\hline $40-50$ & 2,431 & 3,5 & 2,3 & 2,93 & 2,79025 \\
\hline $50-60$ & 3,83 & 3,04 & 2,5 & 3,44 & 3,2025 \\
\hline $65+$ & 3,41 & 2,8 & 4,11 & 3,7 & 3,505 \\
\hline
\end{tabular}

Таблица 2.

Не приведи бог видеть русский бунт,

бессмысленный и беспощадный

\begin{tabular}{|c|c|c|c|c|c|}
\hline Сек. & Сек. & Сек. & Сек. & $\begin{array}{c}\text { Среднее } \\
\text { время про- } \\
\text { чтения }\end{array}$ \\
\hline $20-30$ & 4,6 & 4,32 & 3,541 & 4,8 & 4,31525 \\
\hline $40-50$ & 3,63 & 5,5 & 4,3 & 3,8 & 4,3075 \\
\hline $50-60$ & 5,6 & 4,4 & 3,825 & 5,18 & 4,75125 \\
\hline $65+$ & 4,65 & 5,01 & 5,953 & 6,12 & 5,43325 \\
\hline
\end{tabular}

Таблица 3.

Блажен, кто молча был поэт

\begin{tabular}{|c|c|c|c|c|c|}
\hline Сек. & Сек. & Сек. & Сек. & $\begin{array}{c}\text { Среднее } \\
\text { время про- } \\
\text { чтения }\end{array}$ \\
\hline $20-30$ & 2,2 & 2,2 & 1,9 & 1,9 & 2,05 \\
\hline $40-50$ & 1,67 & 1,67 & 1,84 & 1,87 & 1,7625 \\
\hline $50-60$ & 3,15 & 1,7 & 1,64 & 2,4 & 2,2225 \\
\hline $65+$ & 2,18 & 2,07 & 2,95 & 2,44 & 2,41 \\
\hline
\end{tabular}

Исходя из результатов проведённого исследования, можно заключить, что в каждом предложении прослеживается одна закономерность: все три предложения медленнее всего произносят самые старшие респонденты, чуть быстрее читают респонденты 50-60 лет, ещё чуть более высокая скорость чтения наблюдается у самых младших респондентов (20-30 лет), а самая высокая скорость наблюдалась у группы 40-50 лет.

Таблица 4.

\begin{tabular}{|c|c|c|c|}
\multicolumn{4}{|c}{ Частота основного тона } \\
Возраст & $\begin{array}{c}\text { Средняя частота } \\
\text { основного тона, } \\
\text { минимум Hz }\end{array}$ & $\begin{array}{c}\text { Средняя } \\
\text { частота } \\
\text { основного тона, } \\
\text { максимум Hz }\end{array}$ & $\begin{array}{c}\text { Средняя частота } \\
\text { основного тона Hz }\end{array}$ \\
\hline $20-30$ & 104,8 & 258,83 & 181,815 \\
\hline $40-50$ & 70,813 & 213,51 & 142,1615 \\
\hline $50-60$ & 100,97 & 214,73 & 157,85 \\
\hline $65+$ & 100,812 & 265,03 & 182,921 \\
\hline
\end{tabular}

Исходя из полученных результатов видно, что самый высокий тон частоты основного тона наблюдается у лю- 
дей старше 65 лет, а самый низкий - у группы 40-50 лет, между ними идут группы 50-60 лет и группа 20-30 лет в порядке возрастания.

Таблица 5.

Средняя интенсивность

\begin{tabular}{|c|c|c|c|} 
Возраст & $\begin{array}{c}\text { Средняя } \\
\text { интенсивность, } \\
\text { минимум db }\end{array}$ & $\begin{array}{c}\text { Средняя } \\
\text { интенсивность, } \\
\text { максимум db }\end{array}$ & $\begin{array}{c}\text { Средняя } \\
\text { интенсивность } \\
\mathrm{db}\end{array}$ \\
\hline $20-30$ & 80,944 & 45,93 & 63,437 \\
\hline $40-50$ & 80,13 & 42,9 & 61,515 \\
\hline $50-60$ & 84,36 & 35,74 & 60,05 \\
\hline $65+$ & 83,27 & 38,3 & 60,785 \\
\hline
\end{tabular}

Результаты исследования интенсивности голос совершенно другие. Самая высокая интенсивность голоса у самой молодой группы (20-30 лет), чуть более высокая интенсивность у группы постарше (40-50 лет), за ними идёт групп 65+ лет, а вот самую низкую интенсивность демонстрирует группа 50-60 лет.

Существует предположение, что речь молодых звучит более слитно, для проверки данной теории, с помощью программы PRAAT были выделены длительность каждого слова и каждой паузы, для каждой возрастной группы была посчитана средняя длительность этих показателей (таблица 6, таблица 7), потом результаты были проанализированы.

Таблица 6.

\begin{tabular}{|c|c|c|c|c|}
\multicolumn{7}{|c|}{ Средняя длина слов } \\
\hline В & $20-39$ & $40-49$ & $50-59$ & $65+$ \\
\hline Доме & 0,582 & 0,14 & 0,17 & 0,171 \\
\hline Коменданта & 0,263 & 0,25 & 0,26 & 0,35 \\
\hline Я & 0,82 & 0,69 & 0,81 & 0,89 \\
\hline Был & 0,16 & 0,18 & 0,2 & 0,24 \\
\hline Принят & 0,32 & 0,32 & 0,34 & 0,4 \\
\hline Как & 0,18 & 0,18 & 0,2 & 0,2 \\
\hline Родной & 0,48 & 0,48 & 0,52 & 0,53 \\
\hline Итого & 2,983 & 2,44 & 2,67 & 2,991 \\
\hline
\end{tabular}

Таблица 7.

Средняя длина пауз

\begin{tabular}{|c|c|c|c|c|}
\hline & $20-39$ & $40-49$ & $50-59$ & $65+$ \\
\hline В & 0 & 0 & 0 & 0,01 \\
\hline Доме & 0,05 & 0,042 & 0,06 & 0,05 \\
\hline Коменданта & 0,12 & 0,1 & 0,16 & 0,21 \\
\hline Я & 0 & 0 & 0,012 & 0,012 \\
\hline Был & 0,06 & 0,05 & 0,1 & 0,052 \\
\hline Принят & 0,06 & 0,12 & 0,14 & 0,131 \\
\hline Как & 0 & 0,007 & 0 & 0 \\
\hline Итого & 0,29 & 0,319 & 0,472 & 0,465 \\
\hline
\end{tabular}

Полученные результаты показывают, что самые короткие пазы у молодых людей, соответственно, их речь кажется более нерасчленённой по сравнению с речью более старших поколений. А вот средняя скорость слов респондентов группы 20-30 лет лишь немного быстрее средней скорости.

\section{ЗакАючение}

Возраст, безусловно, оказывает сильное влияние на формирование интонации. Исследование показало, что самой высокой частотой среднего тона обладает самая старшая группа респондентов (люди старше 65 лет), они же говорят почти самым тихим голосом (с очень низкой интенсивностью), что можно объяснить несколькими явлениями: во-первых, у пожилых людей наблюдается потеря тонуса мышечных волокон, что влияет на громкость и высоту голоса, кроме того, как было сказано выше, у людей в пожилом возрасте начинается деградация легочной функции, которая напрямую влияет как на скорость речи, так и на её интенсивность. Представители самой младшей же группы, наоборот, демонстрируют самую высокую интенсивность речи, так как их легкие пока не подвержены старческим патологиям. Кроме того, было доказано, что речь молодых самая слитнозвучащая и нечленораздельная за счёт самой короткой длительности пауз между словами. А респонденты старше 65 лет демонстрируют самую низкой скорость произнесения предложений. Таким образом экспериментальный анализ речи людей разных возрастов успешно подтвердил, что геронтологические изменения влияют на интонацию.

\section{ЛИТЕРАТУРА}

1. К Князев С.В., Пожарицкая С.К. Современный русский литературный язык: Фонетика, орфоэпия, графика и орфография: Учебное пособие для вузов. М.: Гаудеамус, 2011. $426 \mathrm{C}$

2. Интенсивность речи // Департамент развития образовательных ресурсов, Казанский (Приволжский) федеральный университет. URL: http://tulpar.kpfu.

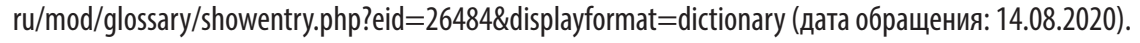

3. Pitch-tracking, или определение частоты основного тона в речи, на примерах алгоритмов Praat, YAAPT и YIN // Habr - сообщество IT-специалистов URL: https://habr.com/ru/company/neurodatalab/blog/416441/ (дата обращения: 14.08.2020) 
4. Интонация // Словарь лингвистических терминов URL: https://slovar.cc/rus/term/1464036.html (дата обращения: 01.11.2020).

5. 应用 Praat 软件分析成人嗓音声学参数 [Использование программного обеспечения Praat для анализа акустических параметров голоса взрослого человека] // Wenku Baidu URL: https://wenku.baidu.com/view/7fb1e754a517866fb84ae45c3b3567ec102ddcef.html (дата обращения: 01.11.2020). 6. Praat: doing phonetics by computer // PRAAT URL: https://www.fon.hum.uva.nl/praat/ (дата обращения: 01.11.2020).

(c) Инь Сяо (superazhen@hotmail.com).

Журнал «Современная наука: актуальные проблемы теории и практики»

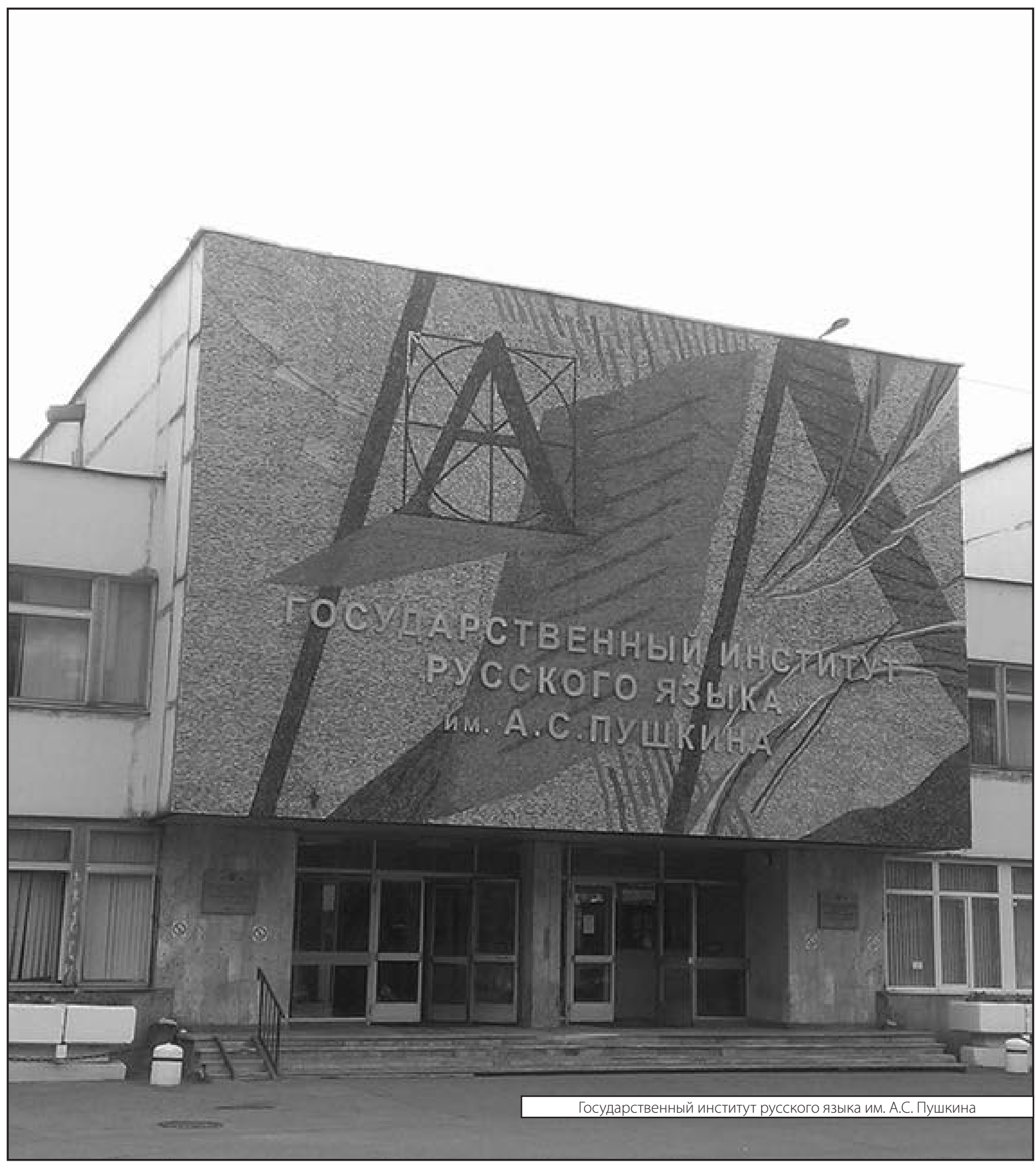

